\title{
THE INFLUENCE OF CHANGES OF ABDOMINAL TENSION UPON PULMONARY FUNCTION
}

\author{
By W. B. KOUNTZ, L. GOTTLIEB AND R. KING \\ (From the Department of Medicine, Washington University School of Medicine, \\ and the Barnes Hospital, St. Louis)
}

(Received for publication June 12, 1936)

Salkin (1) has recently studied normal physiological changes which occur in the abdominal cavity. He has described a process of adaptability in the abdominal muscles which tends to prevent changes in intra-abdominal pressure, and which he terms " abdominal accommodation." He considers this process to be a reflex mechanism dependent upon an intact neuromuscular. system, and points out the clinical bearing on intraperitoneal conditions, and functional interrelationship between the pleural and peritoneal cavities. Previous attempts to obtain measurements of abdominal pressure have been accompanied by difficulties $(2,3,4)$. When fluid is injected at a certain rate into the abdominal cavity hyperbolic curves are obtained in which the pressure rise is slow at first and then becomes more rapid.

Although the physiology of the intra-abdominal pressure and tension of the abdominal wall has been studied in considerable detail, its relation to pressure within the pleural cavity has been insufficiently considered.

Recent clinical observations by Gordon (5) have indicated the importance of change in abdominal pressure upon function of the thorax. $\mathrm{He}$ found that elevation of intra-abdominal pressure during pregnancy apparently influenced the course of chronic pulmonary diseases. In cases of chronic tuberculosis and bronchiectasis, cough, shortness of breath, and excessive sputum were diminished. He attributed the improvement to an increase of the intra-abdominal pressure, which in turn caused elevation of the leaves of the diaphragm.

It has also been shown by Alexander and Kountz (6) that the vital capacity of an individual with chronic pulmonary emphysema may be improved by the application of an abdominal belt, which is believed to increase the intra-abdominal pressure and the tension of the abdominal wall.

\section{EXPERIMENTAL}

To study the influence of abdominal conditions upon intrabronchial and intrapleural pressure, experiments were made upon animals. A bronchoscope was introduced, small hollow copper tubes were inserted into the lower bronchus on each side and were arranged by means of interchangeable tips to occlude the bronchus except for its connection with the lumen of the tube. Rubber tubing was connected to the copper tubes and, by means of a tambour and lever, records on a moving drum were made. Because of secretion, which was partially controlled by atropine, and because of slight movements of the tips, precautions were necessary to assure free excursion with each respiration.

An important part of the study was to determine the effect of cough. This was induced by blowing cigarette smoke directly into the trachea of the partially anesthetized animals. Anesthesia, which consisted of morphine in doses of one and one-half grains with ether only sufficient to permit the passage of the bronchoscope, did not abolish the cough reflex. Measurements of intratracheal, intrapleural, and intra-abdominal pressures could thus be recorded following cough under varying conditions.

For determination of intrapleural pressure two large number fourteen needles were inserted into both pleural cavities, connected to water manometers, and records made upon the moving drum. To record the pressure within the abdominal cavity, a rubber tube with a small balloon attached to its end was introduced through the esophagus into the stomach. This was connected to a mercury manometer, and the balloon distended by air pressure to ten millimeters of mercury.

The effect of both costal and abdominal types of breathing was recorded. Since respiration in the dog is chiefly costal, it was necessary for the production of abdominal breathing to place a binder 
about the chest. Later, for the study of the costal type of respiration, the binder. was removed and pressure was exerted on the abdominal wall.

To study the effect of abdominal conditions upon the ejection of fluid from the lower bronchi, $x$-ray studies were made to learn the time necessary to discharge from the lungs, oil opaque to the $\mathrm{x}$-rays. Under the fluoroscope, tubes were introduced and five cubic centimeters of opaque oil were injected into the bronchus of each lower lobe. X-ray pictures were taken at the time, and subsequently at intervals of three days until all the oil had disappeared.

A factor other than abdominal pressure which may significantly influence abdominal thoracic relationships is the position of the diaphragm, which acts to change the relative size of the two cavities. To study this, two types of operation were performed. In one group of animals the chest was opened, and the diaphragm was attached high on one side by suturing it to the chest. The abdominal cavity was thus increased in size at the expense of the thorax without greatly altering the function of either the thoracic or the abdominal walls. In the other type of operation, the abdominal cavity was opened and the diaphragm attached low by suturing it to the abdominal wall, thus artificially increasing the size of the thoracic cavity and diminishing the abdominal. These operations were done on the left side only. The animal was allowed to recover. From four to six weeks later observations were again made of the bronchial pressure, intrapleural pressure, and of the time that it took to empty oil from the lung.

The normal dog has a much more mobile mediastinum than man, and when the position of the diaphragm was changed on one side a shift of the septum and heart was noted. In the experiments in which the diaphragm was attached low, the mediastinum shifted to that side; when it was attached high it shifted to the opposite side. This change does not usually occur. in man because the mediastinum is more rigid. It was therefore necessary in these experiments to prevent the shifting of the mediastinum in order to approximate more closely the state of the human chest. This was done by injecting ten per cent emulsion of ground glass in mineral oil into the mediastinum and waiting for a period of four weeks before studies were made. In these animals there was little or. no shifting of the mediastinum when the position of the diaphragm was changed by operation. Experiments were performed on a group of twenty animals prepared in this way.

Since it has been demonstrated that abdominal tension and adaptability of the abdominal wall are dependent upon an intact neuromuscular mechanism (1), the abdominal muscles were resected in some animals. In others, nerve section of the anterior roots from the fourth thoracic to the sixth lumbar was performed. In such animals a marked distention of the abdomen occurred. Adaptability of the abdominal muscles to changes in intraabdominal pressure was lost. With these procedures it was possible to determine the effect of changes in abdominal pressure and in the position of the diaphragms upon intrabronchial and intrapleural pressures, and upon the drainage of fluid from the lower bronchi.

\section{RESULTS}

Intra-abdominal pressure. Measurements of abdominal pressure in animals were found to be rather unsatisfactory. With normal respiration, pressures varied from 0 to -3 to $-4 \mathrm{~cm} . \mathrm{H}_{2} \mathrm{O}$. With induced cough, pressures rose from 20 to $30 \mathrm{~mm}$. $\mathrm{Hg}$. In animals with a low diaphragm and a normal abdominal wall the pressure was from 0 to $-2 \mathrm{~cm} . \mathrm{H}_{2} \mathrm{O}$, while during cough the pressure reached higher levels than when the diaphragm was in the normal position. In those with high attachment of the diaphragm the abdominal pressure was usually slightly lower than in the normal animal, especially during cough.

While breathing quietly animals whose abdominal wall had been weakened either by cutting the nerves or by dissection of the muscles showed little variation in abdominal pressure from those with intact muscles. The increase on coughing, however, was much less, the manometer readings ranging between +10 and $+15 \mathrm{~mm}$. $\mathrm{Hg}$.

Measurements of the intrapleural pressure invariably showed approximately normal values in normal animals and in the ones with normal mediastinum, regardless of the position of the diaphragm. This was not the case, however, when the mediastinum had been fixed previous to the operation, for in such animals, compensation for the change in size of the chest cavity on the operated side could not occur. 
TABLE I

Normal dogs

\begin{tabular}{|c|c|c|c|c|c|c|c|c|}
\hline \multirow[b]{2}{*}{ Dog } & \multicolumn{4}{|c|}{ Left side } & \multicolumn{4}{|c|}{ Right side } \\
\hline & $\begin{array}{l}\text { Intra- } \\
\text { pleural } \\
\text { pressure }\end{array}$ & $\begin{array}{c}\text { Intra- } \\
\text { pleural } \\
\text { pressure } \\
\text { during } \\
\text { cough }\end{array}$ & $\begin{array}{l}\text { Pres- } \\
\text { sure } \\
\text { in } \\
\text { lower } \\
\text { lobe } \\
\text { bronchus }\end{array}$ & $\begin{array}{c}\text { Emp- } \\
\text { tying } \\
\text { time } \\
\text { for } \\
\text { oil }\end{array}$ & $\begin{array}{l}\text { Intra- } \\
\text { pleural } \\
\text { pressure }\end{array}$ & $\begin{array}{l}\text { Intra- } \\
\text { pleural } \\
\text { pressure } \\
\text { during } \\
\text { cough }\end{array}$ & $\begin{array}{c}\text { Pres- } \\
\text { sure } \\
\text { in } \\
\text { lower } \\
\text { lobe } \\
\text { bronchus }\end{array}$ & $\begin{array}{c}\text { Emp- } \\
\text { tying } \\
\text { time } \\
\text { of } \\
\text { oil }\end{array}$ \\
\hline & $\mathrm{H}_{2} \mathrm{O}$ & cm. $\mathrm{H}_{2} \mathrm{O}$ & $\mathrm{mm} . \mathrm{Hg}$ & days & $\mathrm{cm} \mathrm{H}_{2} \mathrm{O}$ & $\mathrm{cm}, \mathrm{H}_{2} \mathrm{O}$ & $\mathrm{mm}, \mathrm{Ha}$ & day \\
\hline $\begin{array}{r}1 \\
2 \\
3 \\
4 \\
5 \\
6 \\
7 \\
8 \\
9 \\
10 \\
11 \\
12\end{array}$ & $\begin{array}{ll}-4 & -6 \\
-5 & -8 \\
-8 & -10 \\
-6 & -8 \\
-4 & -6 \\
-4 & -5 \\
-5 & -9 \\
-4 & -7 \\
-4 & -7 \\
-3 & -8 \\
-6 & -10 \\
-5 & -8\end{array}$ & $\begin{array}{l}+40 \\
+50 \\
+48 \\
+62 \\
+40 \\
+38 \\
+40 \\
+46 \\
+54 \\
+48 \\
+51 \\
+44\end{array}$ & 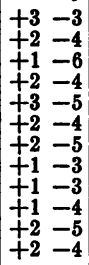 & $\begin{array}{l}18 \\
17 \\
18 \\
19 \\
19 \\
19 \\
19 \\
18 \\
18 \\
21 \\
18 \\
21\end{array}$ & $\begin{array}{ll}-4 & -6 \\
-3 & -5 \\
-4 & -6 \\
-4 & -6 \\
-4 & -6 \\
-5 & -9 \\
-4 & -7 \\
-5 & -7 \\
-4 & -8 \\
-6 & -10 \\
-5 & -10\end{array}$ & $\begin{array}{l}+40 \\
+50 \\
+46 \\
+58 \\
+40 \\
+39 \\
+37 \\
+40 \\
+55 \\
+42 \\
+50 \\
+50\end{array}$ & $\begin{array}{ll}+3 & -3 \\
+2 & -4 \\
+1.5 & -6 \\
+2 & -4 \\
+3 & -5 \\
+2 & -4 \\
+2 & -5 \\
+1.5 & -3 \\
+2 & -3 \\
+2 & -4 \\
+3 & -5 \\
+2.5 & -5\end{array}$ & $\begin{array}{l}18 \\
18 \\
18 \\
19 \\
19 \\
20 \\
20 \\
20 \\
19 \\
19 \\
21 \\
19\end{array}$ \\
\hline
\end{tabular}

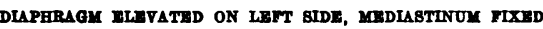

\begin{tabular}{l|ll|l|ll|l|ll|l|ll|l}
\hline 1 & -5 & -12 & +30 & +2 & -3 & 31 & -2 & -4 & +50 & +4 & -3 & 17 \\
2 & -4 & -10 & +38 & +2 & -8 & 28 & -3 & -5 & +53 & +4 & -4 & 18 \\
3 & -8 & -10 & +40 & +3 & -8 & 27 & -2 & -4 & +58 & +3 & -6 & 19 \\
4 & -6 & -12 & +36 & +2 & -6 & 32 & -3 & -4 & +52 & +4 & -4 & 15 \\
5 & -7 & -10 & +50 & +2 & -6 & 28 & -4 & -5 & +48 & +6 & -5 & 18 \\
6 & -4 & -8 & +32 & +2 & -7 & 27 & -2 & -5 & +48 & +4 & -4 & 19 \\
\hline
\end{tabular}

DIAPHRAGM LOW ON LEFT BIDE, MRDIABTINUY FIXED

\begin{tabular}{r|rr|r|rr|r|rr|r|rr|r}
\hline 7 & -2 & -6 & +60 & +4 & -5 & 15 & -4 & -6 & +57 & +2 & -3 & 23 \\
8 & -2 & -5 & +56 & +3 & -2 & 17 & -6 & -8 & +60 & +3 & -5 & 22 \\
9 & -1 & -3 & +62 & +5 & -2 & 16 & -5 & -6 & +55 & +2 & -4 & 21 \\
10 & -1 & -4 & +55 & +4 & -3 & 17 & -7 & -10 & +54 & +1 & -2 & 22 \\
11 & -3 & -5 & +55 & +3 & -3 & 18 & -6 & -9 & +50 & +2 & -2 & 22 \\
12 & -2 & -3 & +52 & +3 & -2 & 15 & -5 & -9 & +56 & +3 & +2 & 21 \\
\hline
\end{tabular}

Intrapleural pressure. With low attachment of the diaphragm, intrapleural pressure on the affected side was elevated during respiration to approximately that of the atmosphere, ranging between +1 to $-2 \mathrm{~cm}$. of water. This contrasted with a pressure of -4 to $-6 \mathrm{~cm}$. of water on the unaffected side or in an intact animal.

In animals with the diaphragm attached high and the mediastinum fixed, the intrapleural pressure was found to be more negative, -6 to -10 $\mathrm{cm}$. of water. Weakening of the abdominal wall tended to make the intrapleural pressure more nearly atmospheric than had been observed previously in the same animal.

Emptying time of fluid from bronchi. In normal animals our experience with opaque oil confirmed that of Carlson et al. (7) and his coworkers, who found that oil was expelled from the lungs in from 18 to 21 days. In animals with a diaphragm attached low and with a normal abdominal wall, the oil was expelled from the bronchus of the operated side in 15 to 17 days, whereas on the opposite side it remained for. 22 days. In animals with a diaphragm attached high the oil was expelled in about four weeks, whereas on the opposite unoperated side the normal time of 19 days was usually observed. In animals with a weakened abdominal wall, the time of expulsion was greatly prolonged, lasting approximately 30 days.

TABLE II

Normal abdominal wall, nerves cut, mediastinum fixed

\begin{tabular}{|c|c|c|c|c|c|c|c|c|}
\hline \multirow[b]{2}{*}{ Dog } & \multicolumn{4}{|c|}{ Left } & \multicolumn{4}{|c|}{ Right } \\
\hline & $\begin{array}{c}\text { Intra- } \\
\text { pleural } \\
\text { pressure }\end{array}$ & $\begin{array}{c}\text { Intra- } \\
\text { pleural } \\
\text { pressure } \\
\text { during } \\
\text { cough }\end{array}$ & $\begin{array}{c}\text { Pres- } \\
\text { sure } \\
\text { in } \\
\text { lower } \\
\text { lobe } \\
\text { bronchus }\end{array}$ & $\begin{array}{c}\text { Emp- } \\
\text { tying } \\
\text { time } \\
\text { of } \\
\text { oil }\end{array}$ & $\begin{array}{c}\text { Intra- } \\
\text { pleural } \\
\text { pressure }\end{array}$ & $\begin{array}{c}\text { Intra- } \\
\text { pleural } \\
\text { pressure } \\
\text { during } \\
\text { cough }\end{array}$ & $\begin{array}{c}\text { Pres- } \\
\text { sure } \\
\text { in } \\
\text { lower } \\
\text { lobe } \\
\text { bronchus }\end{array}$ & $\begin{array}{c}\text { Emp- } \\
\text { tying } \\
\text { time } \\
\text { of } \\
\text { oil }\end{array}$ \\
\hline $\begin{array}{l}1 \\
2 \\
3 \\
4 \\
5\end{array}$ & $\begin{array}{cc}\mathrm{cm} . \mathrm{H}_{2} \mathrm{O} \\
-4 & -5 \\
-3 & -5 \\
-4 & -6 \\
-4 & -8 \\
-3 & -6\end{array}$ & $\begin{array}{c}\text { cm. } \mathrm{H}_{2} \mathrm{O} \\
+30 \\
+25 \\
+22 \\
+17 \\
+24\end{array}$ & $\begin{array}{l}m m . H g \\
+3-3 \\
+2-3 \\
+2-3 \\
+2-4 \\
+1-3\end{array}$ & $\begin{array}{c}\text { days } \\
24 \\
30 \\
27 \\
26 \\
30\end{array}$ & $\begin{array}{cc}\mathrm{cm} . \mathrm{H}_{2} \mathrm{O} \\
-4 & -6 \\
-3 & -5 \\
-4 & -6 \\
-4 & -7 \\
-3 & -6\end{array}$ & $\begin{array}{c}\mathrm{cm} . \mathrm{H}_{2} \mathrm{O} \\
+30 \\
+32 \\
+21 \\
+20 \\
+22\end{array}$ & $\begin{array}{cc}m m . & H a \\
+3 & -3 \\
+2 & -3 \\
+2 & -3 \\
+2 & -4 \\
+1 & -3\end{array}$ & $\begin{array}{c}\text { days } \\
32 \\
31 \\
27 \\
29 \\
34\end{array}$ \\
\hline
\end{tabular}

DLAPHRAGM HIGH, ABDOMINAL NERVFS CUT, MEDLATTINUM FIXED

\begin{tabular}{l|cc|c|cc|c|cc|c|c|c}
\hline 1 & -2 & -3 & +22 & +3 & -2 & 40 & -4 & -6 & +32 & $+3-3$ & 28 \\
3 & -1 & -4 & +18 & +3 & -2 & $\begin{array}{c}45 \\
\text { Not out }\end{array}$ & -3 & -6 & +28 & $+2-2$ & 27 \\
4 & -2 & -4 & +15 & +2 & -2 & $\begin{array}{c}\text { Not out } \\
\text { at 40 } \\
\text { days }\end{array}$ & -4 & -7 & +35 & $+2-3$ & 29 \\
5 & -1 & -3 & +18 & +1 & -1 & $\begin{array}{c}\text { Not out } \\
\text { at 40 } \\
\text { days }\end{array}$ & -4 & -7 & +24 & $+1-3$ & 32 \\
\hline
\end{tabular}

DIAPHRAGK LOW, ABDOMINAL NERTES CUT, MEDIASTINOM TLED

\begin{tabular}{|c|c|c|c|c|c|c|c|c|}
\hline $\begin{array}{l}1 \\
2 \\
3 \\
4 \\
5\end{array}$ & $\begin{array}{ll}-1 & -5 \\
-4 & -7 \\
+5 & -6 \\
-3 & -5 \\
-3 & -8\end{array}$ & $\begin{array}{l}+34 \\
+50 \\
+58 \\
+56 \\
+44\end{array}$ & 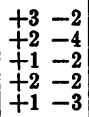 & $\begin{array}{l}18 \\
19 \\
23 \\
27 \\
16\end{array}$ & $\begin{array}{ll}-3 & -6 \\
-2 & -5 \\
-1 & -8 \\
-3 & -4 \\
-4 & -8\end{array}$ & $\begin{array}{l}+38 \\
+31 \\
+40 \\
+22 \\
+28\end{array}$ & $\begin{array}{ll}-1 & -6 \\
-4 & -8 \\
-5 & -6 \\
-3 & -6 \\
-3 & -8\end{array}$ & $\begin{array}{l}22 \\
29 \\
30 \\
26 \\
21\end{array}$ \\
\hline
\end{tabular}

Bronchial pressure. In the normal animal bronchial pressure varied from $-1 \mathrm{~mm}$. $\mathrm{Hg}$ during inspiration to $+1 \mathrm{~mm}$. $\mathrm{Hg}$ during expiration. During the expiratory phase of cough, the pressure rose as high as 30 to $40 \mathrm{~mm}$. $\mathrm{Hg}$. In normal animals with continuous irritation of the bronchus, cough was frequently sustained for 15 to 30 seconds, a result which could not be obtained, however, when the abdominal wall was weakened by removal of muscles.

In animals with fixed mediastinum, on the side with the high diaphragm there is more negative bronchial pressure during inspiration, both with cough and without; on the side with the low diaphragm, the bronchial pressure was abnormally 
low during the inspiratory phase and usually higher during the expiratory phase.

\section{DISCUSSION}

Because of the accommodation of the abdominal muscles, exact measurements of pressure and of variations in abdominal pressure are difficult to determine. From this group of experiments one factor which has been previously neglected appears to be clearly established; the abdominal pressure cannot function normally in animals with lax abdominal walls. Although abdominal pressure under such conditions does not vary greatly, its effect on thoracic function is altered or lessened, a fact which is demonstrated by a study of intrapleural and intrabronchial pressures before and after section of the abdominal muscles. This was particularly apparent following cough. Sustained coughing, which occurs frequently in normal animals with irritation of the trachea and bronchi, cannot be induced in animals with weakened abdominal walls.

We believe that the more nearly atmospheric intrapleural pressure on the side with the low diaphragm is due to distention of the lung and to diminished action of the muscles of the chest on that side. The lung is thus chronically distended and approaches the functional state of emphysema, although no anatomical changes suggesting this condition occurred. The more negative intrapleural pressure which occurred with a high diaphragm could possibly be explained on the basis of decreased activity of areas of lung with increased activity of other areas, a phenomenon similar to that observed in early lobar pneumonia. Another more likely explanation, however, has been suggested by Graham (9). He pointed out that thickening of the pleura due to adhesions and fibrosis may have been a factor in the low intrapleural pressure because of the increased resistance of the fibrous tissue to lung expansion.

Drainage of the lungs as determined by study of the time necessary to expel opaque oil readily establishes that a low diaphragm acted upon by a normal intra-abdominal pressure produces better drainage, whereas a high diaphragm with the same abdominal pressure is conducive to poor drainage of the lower lobes of the lungs. This finding is in agreement with the observations by Graham et al. (8). He noted that in cases with basal bronchiectasis, operations to interrupt the phrenic nerve are often followed by serious consequences to the patient as a result of interference with drainage through the tracheobronchial tree. Weakened abdominal musculature leads to poor drainage of the lung regardless of the position of the diaphragm.

\section{SUMMARY AND CONCLUSIONS}

These experiments suggest that from the standpoint of effective respiration and of pulmonary drainage there is an optimum position of the diaphragm. Since this is dependent, among other factors, upon abdominal tension, any change in pressure within the abdomen may influence pulmonary function. For optimum drainage from the lower portions of the lung a low position of the diaphragm is essential During cough this permits a more positive expiratory bronchial pressure. The low position, however, appears to be conducive to less effective respiration, as shown by a decreased negative intrapleural pressure with normal or forced breathing. This clinically resembles the state of emphysema with low diaphragm and a diminished negative pressure.

A high position of the diaphragm appears to be conducive to fair respiratory function, as indicated by a more negative intrapleural pressure, but is less effective from the standpoint of lung drainage, as judged by the time necessary for the expulsion of opaque oil from the bronchus. It was also noted, in animals with a high diaphragm, that the expiratory bronchial pressure during cough was less than that found in normal animals. A clinical counterpart of such a condition is atelectasis of the lung. The effect of a high position of the diaphragm should also be considered in bronchiectasis and in lobar pneumonia.

\section{BIBLIOGRAPHY}

1. Salkin, David, Intra-abdominal pressure and its regulation. Am. Rev. Tuberc., 1934, 30, 436.

2. Overholdt, R. H., Intraperitoneal pressure. Arch. Surg., 1931, 22, 691.

3. Coombs, H. C., The mechanism of the regulation of intra-abdominal pressure. Am. J. Physiol., 1928, 61, 159. 
4. Wagoner, G. W., Studies on intra-abdominal pressure. I. Negative intra-abdominal pressure as a normal condition. Am. J. M. Sc., 1926, 171, 697.

5. Gordon, Burgess, The mechanism and use of abdominal supports and the treatment of pulmonary diseases. Am. J. M. Sc., 1934, 187, 692.

6. Alexander, H. L., and Kountz, W. B., Symptomatic relief of emphysema by an abdominal belt. Am. J. M. Sc., 1934, 187, 687.
7. Carlson, H. A., Ballon, H. C., Wilson, H. M., and Graham, E. A., The effect of phrenicectomy upon cough and expectoration. A study based upon the elimination of lipiodol and foreign bodies from the lungs. J. Thoracic Surg., 1933, 2, 573.

8. Graham, E. A., Singer, J. J., and Ballon, H. C., Surgical Diseases of the Chest. Volume I. Lea and Febiger, Philadelphia, 1935, p. 642.

9. Graham, E. A., Personal communication. 